\title{
Effect of vibration during local anesthesia administration on pain, anxiety, and behavior of pediatric patients aged 6-11 years: A crossover split-mouth study
}

\author{
Kuthpady Manasa Hegde, Neeraja R, lla Srinivasan, Murali Krishna D R, Anjana Melwani, Sreeraksha Radhakrishna \\ Department of Pediatric ad Preventive Dentistry, MR Ambedkar Dental College and Hospital, Bengaluru, Karnataka, India
}

\begin{abstract}
Background: Uncooperative behavior of children due to dental anxiety may interfere with the effective delivery of dental care and compromise the quality of treatment provided. Injection of local anesthesia is one of the most anxiety-inducing stimuli in pediatric dentistry. This study aimed to compare the efficacy of a child-friendly device, having a combined effect of vibration and distraction, with the conventional method of injection on pain, anxiety, and behavior of pediatric patients aged 6-11 years.

Methods: This randomized, crossover, split-mouth study included 30 children requiring a bilateral inferior alveolar nerve block. The children were equally divided into two groups: group 1, aged 6-8 and group 2, aged 9-11 years. All children were injected with anesthesia using the conventional and device method in two separate sessions. They were assessed for anxiety by measuring the pulse rate before and during the administration of local anesthesia. Behavior was assessed using Faces, Legs, Activity, Cry, Consolability (FLACC) scale, and the child's experience while receiving anesthesia was assessed using the Wong Bakers Pain Rating Scale.

Results: Results showed that the children who received local anesthesia using the device method had a lower mean pulse rate, FLACC scores, and pain rating scores than those who received local anesthesia using the conventional method.

Conclusion: The device method was more effective than the conventional method in managing pain, anxiety, and behavior of patients aged 6-11 years. The device is a cost effective, simple, and child-friendly product for administrating local anesthesia in pediatric patients.
\end{abstract}

Keywords: Behavior; Distraction; Local Anesthesia; Pain; Pediatric Dentistry; Vibration.

This is an Open Access article distributed under the terms of the Creative Commons Attribution Non-Commercial License (http://creativecommons.org/licenses/by-nc/4.0/) which permits unrestricted non-commercial use, distribution, and reproduction in any medium, provided the original work is properly cited.

\section{INTRODUCTION}

Pain is "an unpleasant sensory or emotional experience associated with actual or potential tissue damage" as defined by the World Health Organization in 2015. Effective control of pain in a pediatric patient during dental treatment is the foundation of a successful behavior management [1]. Prevention of pain can promote a positive relationship between the dentist and child, build trust, allay fear and anxiety, and inculcate positive dental attitudes for future treatment [2].

The administration of local anesthesia is the key to controlling pain during dental procedures. Most of the pediatric patients are fearful and anxious about the pain that they experience while the local anesthesia is

Received: February 8, 2019 - Revised: May 7, 2019 - Accepted: June 17, 2019

Corresponding Author: Kuthpady Manasa Hegde, Department of Pediatric ad Preventive Dentistry, MR Ambedkar Dental College and Hospital, Bengaluru, Karnataka, India-560005

Tel: +91620453231 E-mail: kmanasahegde@gmail.com

Copyright(c) 2019 Journal of Dental Anesthesia and Pain Medicine 
administered [3]. Thus, various techniques have been attempted to effectively control the pain during injection, such as warming, buffering, and adjusting the rate of local anesthesia infiltration [4]; pre-cooling the injection [5]; vibration using modern devices like VibraJect [3]; DentalVibe [6]; acupuncture [7]; distraction techniques [8-10]; hypnosis [11]; application of topical anesthesia [12]; and use of computer-controlled anesthesia delivery system (e.g., Wand) [13]. However, to date, no standard injection method has been established.

The analgesic effect of vibration can be explained by the gate control theory of pain. It suggests that pain is transmitted from the peripheral nervous system to the central nervous system where it is modulated by a gating system in the dorsal horn of the spinal cord. More specifically, the afferent pain receptors, i.e., the A-delta fibers carrying acute pain signals triggered by injection and unmyelinated slower $\mathrm{C}$ fibers carrying chronic pain signals, are blocked by fast non-noxious motion nerves called A-beta caused by vibrations [14].

Distraction is a behavior management technique that involves diverting children's attention away from painful stimuli during invasive dental procedures. It can be used most effectively when it is adapted to the developmental level of the child. Thus, distraction is safe, inexpensive, and reduces the time and number of people required to perform the procedure [15].

An attempt was made to put both these techniques in a child-friendly toy and was used for reducing pain and anxiety during dental injection. Hence, this study aimed to evaluate the pain, anxiety, and behavior perception of pediatric patients using a combination of vibration and distraction and compare the results with those using the traditional injection technique during dental procedures.

Materials and methods

This randomized, crossover, split-mouth, clinical study was conducted in the Department of Pediatric and Preventive Dentistry, M.R Ambedkar Dental College and Hospital, after obtaining approval from the institutional review board and ethics committee (IRB number: EC-537) and written informed consent from the parents and verbal assent form from children involved in the study.

The sample size was estimated using GPower software v.3.1.9.2, with an effect size of $53 \%$ [based on the pilot study results], power of $80 \%$, and margin of error of $5 \%$. The required sample size was 29 children, which was rounded off to 30 children ( 15 boys and 15 girls). The children were distributed equally into two groups according to age (group 1, 6-8 years; group, 2 9-11 years) as dental treatment might evoke varied levels of fear and anxiety at different age group/developmental levels [16].

Patients requiring a bilateral inferior alveolar nerve block, without any history of receiving dental injections, and whose behavior was rated as 3 using the Frankel behavior rating scale were included [17]. Patients with acute signs and symptoms requiring emergency treatment, with previous painful dental experience, and who were medically compromised were excluded from the study.

Children in each age group were treated in two different appointments where they were further randomly distributed. Of the total sample, 15 children were treated using the device in the first appointment and using the conventional method in the second appointment. The remaining 15 children were treated with conventional and device method during the first and second appointments, respectively, to avoid preference bias.

All treatment procedures were carried out by one pediatric dentist. With regard to the conventional method of injection, topical anesthetic spray was applied at the injection site and local anesthesia was administered. With regard to the use of the device method, the device (Fig. 1) was first shown to the child and the parent. The children were allowed to touch and turn on the device to familiarize it and not become apprehensive about it. The device was then placed about 2 centimeters away from the injection site (near the angle of mandible) for 2 minutes and local anesthesia was administrated.

The pulse rate was noted using a portable pulse oximeter device (model no 6500; Nidek Medical Pvt. Ltd.), which was attached to the left index finger for about 5 min prior local anesthesia administration. Baseline pulse 


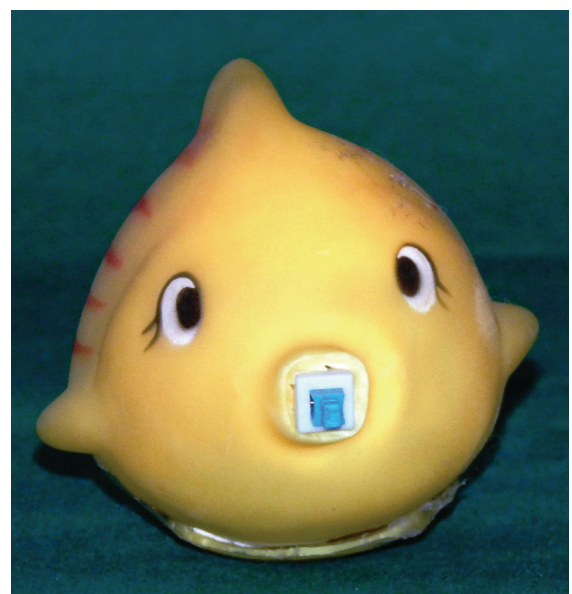

Fig. 1. The photo depicts the device used in the study.

rate was recorded in both appointments just before injecting the anesthesia, and a third person noted the pulse rate during the administration of local anesthesia. The operator rated the child's behavior using the Faces, Legs, Arms, Crying, Consolability (FLACC) behavior pain scale [18] after local anesthesia administration, and the child was asked to rate his or her pain experience using the Wong Bakers Pain Rating Scale [19].

The obtained data were used in the statistical analysis. Wilcoxon signed rank test was used to compare the mean pain scores recorded using the Wong-Baker FACES Pain rating scale and the mean pulse oximeter readings before and during interventions using the conventional and device methods in both groups. McNemar's test was used to compare the FLACC scores of both groups during the administration of local anesthesia using both conventional and device methods. All statistical analyses were performed using the SPSS statistical software package version 22.0 .

\section{RESULTS}

The FLACC scores showed that a higher proportion of patients in both age groups were relaxed while the anesthesia was administered using the device method, indicating a better behavior. A number of patients were relaxed or showed mild discomfort while receiving

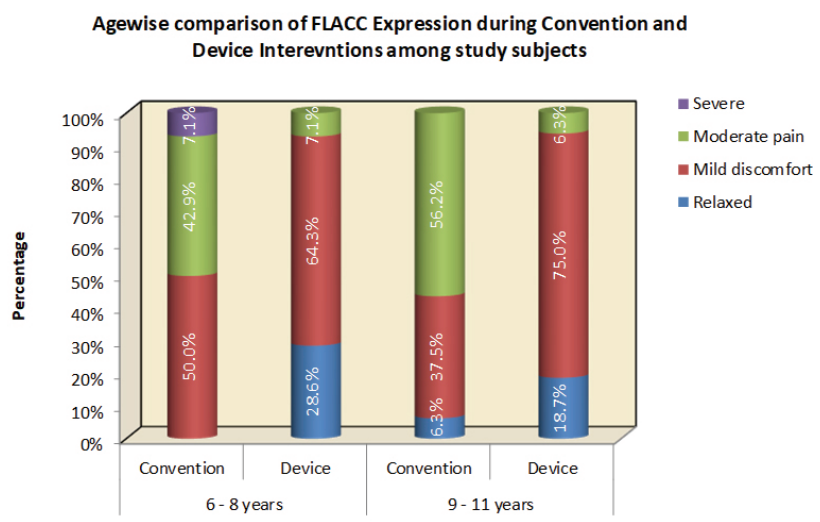

Fig. 2. This figure shows the comparison of Faces, Legs, Activity, Cry, Consolability scores between the two age groups during local anesthesia administration using conventional and device methods among the study subjects.

anesthesia using the device method, whereas a larger number of patients experienced moderate pain while receiving anesthesia using the conventional method (Fig. 2). After receiving local anesthesia using the conventional and device method, the FLACC scores of groups 1 and 2 were compared and the results were statistically significant $(\mathrm{P}=0.01$ and $\mathrm{P}=0.01$, respectively).

There was a reduction in mean pulse rate during the administration of local anesthesia using the device method, which indicates a lower level of anxiety (Fig. 3). The mean baseline pulse rate and pulse rate during treatment using the conventional method were $99.57 \mathrm{bpm}$ and $103.93 \mathrm{bpm}$ (standard deviation [SD]: 8.72 and 9.45, respectively) in group 1 and 95.94 bpm and 98 bpm (SD: 9.21 and 8.20, respectively) in group 2. The mean baseline pulse rate and pulse rate during treatment using the device method were $98.21 \mathrm{bpm}$ and $95.43 \mathrm{bpm}$ (SD: 6.44 and 9.12, respectively) in group 1 and $94.5 \mathrm{bpm}$ and 92.13 bpm (SD: 7.15 and 4.95, respectively) in group 2. The pulse rates of groups 1 and 2 during the procedure using the conventional and device methods were compared, and the results were statistically significant $(\mathrm{P}$ $=0.02$ and $\mathrm{P}=0.01$, respectively). By contrast, there was no significant difference in the baseline pulse rate readings while using the conventional and experimental methods in both groups. The baseline pulse rate of groups 1 and 2 using the conventional and device methods were 


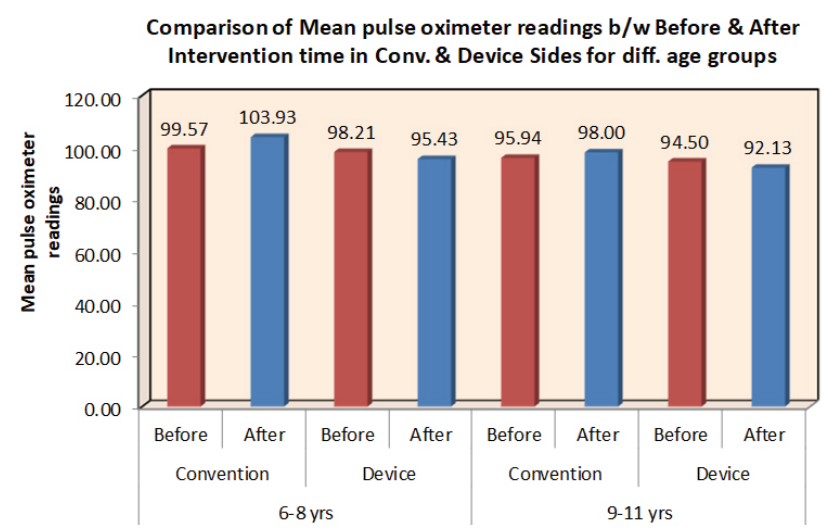

Fig. 3. This figure shows the comparison of mean pulse oximeter readings before and after intervention between the two age groups using conventional and device methods.

compared, and the results were not statistically significant ( $\mathrm{P}=0.57$ and $\mathrm{P}=0.44$, respectively).

Both groups had lower mean Wong Bakers Pain Rating score when using the device method than when using the conventional method (Fig. 4). The mean pain score of group 1 when using the conventional method was 7.43 (SD: 2.14) and that when using the device method was 4.29 (SD: 1.54). The mean pain score of group 2 when using the conventional method was 7.69 (SD: 2.68), and that when using the device method was 4.75 (SD: 2.62). These findings indicated that children experienced less pain when using the device method. The mean pain rating scores of group 1 and group 2 were compared, and the results were statistically significant $(\mathrm{P}=0.008$ and $\mathrm{P}=$ 0.02 , respectively).

\section{DISCUSSION}

Fear of dentists and dental procedures and the associated anxiety are common among children. Age is among the factors that influences the level of dental anxiety among pediatric patients. Patients aged 6-11 years were selected for the study because children in this age group have good cognitive skills.

The device is reusable, battery operated, and a vibrating toy fish containing two vibrator motors of 1.5 volts attached to a 9-watt battery.

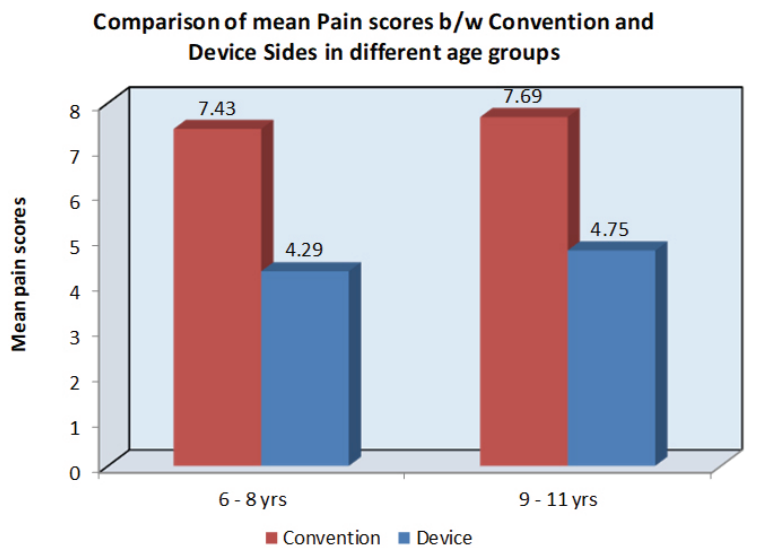

Fig. 4. This figure shows the comparison of mean pain scores between the two age groups using conventional and device methods.

Pulse rate is a direct measure of physiological arousal in humans. Changes in pulse rate are attributed to stress during dental procedures; hence, it can be an index of the patient's response to dental stimuli. During the child's first dental visit, the common reported response to dental stimuli would be fear or anxiety; thus, measuring pulse rate using a pulse oximeter is an objective measure of anxiety levels in children. It has also been used in various studies to measure anxiety in children during dental treatment [20]. In the present study, there was a reduction in mean pulse rate during the administration of local anesthesia using the device method, indicating that the level of anxiety of children is reduced when the device method is used for a dental injection.

The FLACC Behavioral Pain Rating Scale comprises behavioral categories and a variety of descriptors that are reliably associated with pain in children, adults with cognitive impairment, and critical illness, supporting the validity of this tool in these groups.

Recent studies have used the FLACC scale to rate the behavior of children during dental treatment [21]. In the present study, a majority of children showed mild discomfort during anesthesia administration using the device method, whereas a majority of children experienced moderate pain during anesthesia administration using the conventional method.

Several pain rating scales are available and were developed primarily for young children. The Wong-Baker 


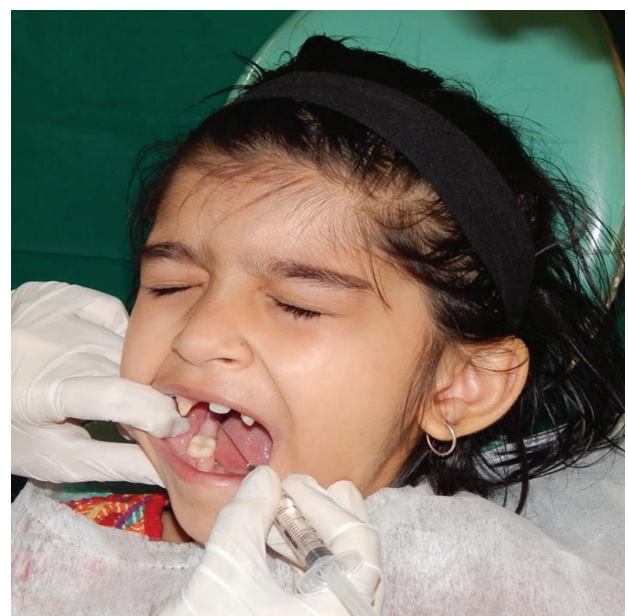

Fig. 5. This figure shows the administration of local anesthesia using the conventional method.

Faces Pain Rating Scale is repeatable, is easy to use, and has been proven to have a significant positive correlation. It has been used for pain assessment in children and adults in various studies [14]. Hence, Wong-Baker Faces Pain Rating Scale was used in the present study. In the present study, the mean pain scores using the device method were lower than those using the conventional method, indicating that children experienced less pain when using the device method.

Gate control theory of pain by Melzack and Wall can be used to explain the analgesic effect of vibration, which was prescribed to minimize concurrent pain. Similar findings were observed by Chaudary et al. using VibraJect in children [3], Shilpapriya et al. using dental vibe in children [1], and Aminah et al. using extra-oral massager [14]. However, extra-oral vibration using a child-friendly device is the first of its kind used in the present study for alleviating pain in children during dental injection.

Distraction is a behavior management technique which involves distracting the patient away from the stimuli that caused the anxiety and thereby reducing it. The objective of this technique is to relax the patient and reduce anxiety during treatment. According to previous studies, the ideal distracter should possess optimal amount of attention, which involves the use of multiple sensory modalities (visual, auditory, and kinesthetic), active emotional

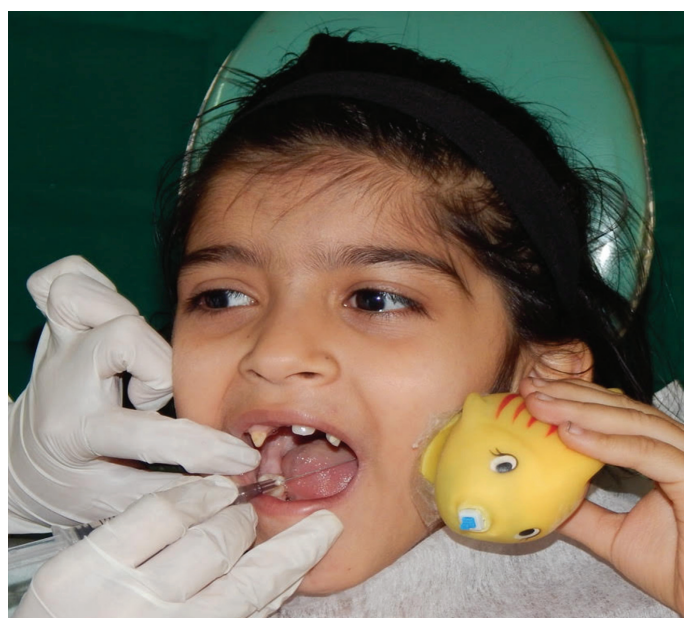

Fig. 6. This figure shows the administration of local anesthesia using the device method.

involvement, and participation of the patient to compete with the signals from the noxious stimuli [22].

Active forms of distraction promote a child's participation involving different sensory components such as interactive toys, virtual reality, controlled breathing, guided imagery and relaxation, and writing in the air using their leg. Conversely, the passive forms can be used for distraction by asking a child to observe an activity or stimulus rather than allowing them to explicitly involve in a certain activity such as listening to music or watching television [23]. In the present study, a toy fish with vibrations was used to distract their thought and attention to the needle, which worked excellently.

In the present study, both age groups showed reduced pain and lower anxiety levels and positive behavior during local anesthesia administration while using the device. This finding indicated that the device is effective in both younger and adolescent age groups for better clinical outcomes (Fig. 5, 6).

Various other systems used to reduce pain during injection were Wand and computer-controlled injection system for children; however, the major disadvantages projected with these system are the time taken to administer the local anesthesia and the cost and complexity of the equipment $[24,20]$.

In the present study, a novel, simple, and child-friendly device with a combined effect of vibration and distraction 
was constructed and used to reduce pain, lessen anxiety, and inculcate positive behavior in children during dental injections. The advantage of using this device is that it is compact, cost effective, and easy to use and have benefits of both vibration and distraction.

No previously published studies have used the vibration technique extra-orally in a child-friendly toy for reducing pain and anxiety during dental injections. Hence, we decided to conduct a study using such a device. However, more extensive studies with larger sample sizes should be conducted to obtain more statistically significant results and make it commercially available.

In this study, the device has proven to be superior than the conventional method of dental injection in reducing pain and anxiety and in managing the child's behavior during dental injection. It is a novel, simple, effective, and child-friendly device, which can result in improved outcomes related to fear and anxiety of dental treatment.

\section{AUHOR ORGIDS}

Kuthpady Manasa Hegde: https://orcid.org/0000-0001-7801-1760

Neeraja R: https://orcid.org/0000-0002-5746-3060

Ila Srinivasan: https://orcid.org/0000-0001-9584-6954

Murali Krishna D R: https://orcid.org/0000-0002-8189-6667

Anjana Melwani: https://orcid.org/0000-0001-5457-9095

Sreeraksha Radhakrishna: https://orcid.org/0000-0002-2385-408X

ACKNOWLEDGEMENTS: The authors would like to thank and acknowledge our parents for their continuous support throughout our lives, the staff of the department of pediatric and preventive dentistry and M.R. Ambedkar Dental College for their delightful insight during the study, and Dr. Santhosh for helping us with statistical analysis.

DECLARATION OF INTERESTS: The authors declare that they have no financial or competing interests.

FUNDING: The authors did not receive funding/financial support.

NOTE: Previous presentation in conference: $40^{\text {th }}$ ISPPD National Conference on October 24, 2018 in Nagpur, India
PATIENT CONSENT FOR PUBLICATION: The authors have obtained from parents a written informed consent for publication of patient's face in a medical publication.

\section{REFERENCES}

1. Shilpapriya M, Jayanthi M, Reddy VN, Sakthivel R, Selvaraju G, Vijayakumar P. Effectiveness of new vibration delivery system on pain associated with injection of local anaesthesia in children. J Indian Soc Pedod Prev Dent 2015; 33: 173-6.

2. Abdelmoniem SA, Mahmoud SA. Comparative evaluation of passive, active, and passive-active distraction techniques on pain perception during local anaesthesia administration in children. J Adv Res 2016; 7: 551-6.

3. Chaudhry K, Shishodia M, Singh C, Tuli A. Comparative evaluation of pain perception by vibrating needle (Vibraject $^{\mathrm{TM}}$ ) and conventional syringe anaesthesia during various dental procedures in pediatric patients: a short study. Int Dent Med J Adv Res 2015; 1: 1-5.

4. Colaric KB, Overton DT, Moore K. Pain reduction in lidocaine administration through buffering and warming. Am J Emerg Med 1998; 16: 353-6.

5. Mohiuddin I, Setty JV, Srinivasan I, Desai JA. Topical application of local anaesthetic gel vs ice in pediatric patients for infiltration anaesthesia. J Evol Med Dent Sci 2015; 4: 12934-40.

6. Ungor C, Tosun E, Dayisoylu EH, Taskesen F, Senel FC. The effects of vibration on pain and anxiety during local anaesthesia administration. JSM Dent. 2014; 2: 1022.

7. Usichenko TI, Wolters P, Anders EF, Splieth C. Acupuncture reduces pain and autonomic distress during injection of local anesthetic in children. Clin J Pain 2016; 32: $82-6$.

8. Navit S, Johri N, Khan SA, Singh RK, Chadha D, Navit $\mathrm{P}$, et al. Effectiveness and comparison of various audio distraction aids in management of anxious dental paediatric patients. J Clin Diagn Res 2015; 9: ZC05-9.

9. Nuvvula S, Alahari S, Kamatham R, Challa RR. Effect of audiovisual distraction with $3 \mathrm{D}$ video glasses on dental 
anxiety of children experiencing administration of local analgesia: a randomised clinical trial. Eur Arch Paediatr Dent 2015; 16: 43-50.

10. Aminabadi NA, Farahani RM, Balayi Gajan E. The efficacy of distraction and counterstimulation in the reduction of pain reaction to intraoral injection by pediatric patients. J Contemp Dent Pract 2008; 9: 33-40.

11. Ramírez-Carrasco A, Butrón-Téllez Girón C, SanchezArmass O, Pierdant-Pérez M. Effectiveness of Hypnosis in Combination with Conventional Techniques of Behaviour Management in Anxiety/Pain Reduction during Dental Anesthetic Infiltration. Pain Res Manag 2017; 2017: 1434015

12. O'Brien L, Taddio A, Lyszkiewicz DA, Koren G. A critical review of the topical local anesthetic amethocaine (Ametop) for pediatric pain. Paediatr Drugs 2005; 7: 41-54.

13. Dubey A, Singh BD, Pagaria S, Avinash A. The Wand: A Mini Review of an Advanced Technique for Local Anaesthesia Delivery in Dentistry. Am J Adv Drug Deliv 2014; 30: 1-6.

14. Aminah M, Nagar P, Singh P, Bharti M. Comparison of topical anesthetic gel, pre-cooling, vibration and buffered local anaesthesia on the pain perception of pediatric patients during the administration of local anaesthesia in routine dental procedures. J Int Med Res 2017; 4: 400-3.

15. Singh H, Rehman R, Kadtane S, Dalai DR, Jain CD. Techniques for the behaviours management in pediatric dentistry. Int J Sci Study 2014; 2: 269-72.

16. Majstorovic M, Veerkamp JS. Developmental changes in dental anxiety in a normative population of Dutch children. Eur J Paediatr Dent 2005; 6: 30-4.

17. Mathewson RJ, Primosch RE. Fundamentals of Pediatric Dentistry. 3rd ed. Quintessence Publishing Co. 1995, p17. 18. Merkel SI, Voepel-Lewis T, Shayevitz JR, Malviya S. The FLACC: a behavioural scale for scoring postoperative pain in young children. Pediatr Nurs 1997; 23: 293-7.

19. Wong DL, Baker CM. Pain in children: comparison of assessment scales. Pediatr Nurs 1988; 14: 9-17.

20. Deepak V, Challa RR, Kamatham R, Nuvvula S. Comparison of a new auto-controlled injection system with traditional syringe for mandibular infiltrations in children: A randomized clinical trial. Anesth Essays Res 2017; 11: $431-8$.

21. Melwani AM, Srinivasan I, Setty JV, Pamnani SS, Lalitya D. A clinical comparative study between conventional and camouflaged syringes to evaluate behaviour and anxiety in 6-11-year-old children during local anaesthesia administration - a novel approach. J Dent Anesth Pain Med 2018; 18: 35-40.

22. Peretz B, Efrat J, Dental anxiety among young adolescent patients in Israel. Int J Paediatr Dent 2000; 10: 126-32.

23. Allani S, Setty JV. Effectiveness of distraction techniques in the management of anxious children in the dental operatory. IOSR J Dent Med Sci 2016; 15: 69-73.

24. González-Castro O, Arias A. Controlled flow of dental anesthesia solution to reduce pain and anxiety. Int J Clin Anesthesiol 2017; 5: 1075. 